\title{
Response latency as a tool to study L2 Learners' ZPD, ZAD and ongoing information processing
}

\author{
Iman Bakhoda* and Karim Shabani
}

\author{
* Correspondence: \\ bakhodaiman@gmail.com \\ Allameh Mohaddes Nouri University, \\ Nour, Mazandaran, Iran
}

\begin{abstract}
Introduction: Under the influence of Vygotsky, dynamic assessment (DA) has recently crept into the realm of $L 2$ testing to assess learners' cognitive modification through the concept of mediation and zone of proximal development (ZPD) (Ableeva, The Effects of Dynamic Assessment on L2 Listening Comprehension 2008; Lantolf, Sociocultural theory and the pedagogical imperative 2010). Computerized dynamic assessment (C-DA) is introduced as a technological offshoot of DA which has the applicability to provide a more vivid picture of learners cognitive functioning (Poehner, 2008). DA proponents proposed that the presentation of mediations is the only option to assess and assist learners' ZPD and cognitive functioning.

Result: In this study, response latency (RL), with the potentiality to analyze on-going information processing of mind, is employed as a measurement tool in assessing learners' cognitive functioning via C-DA form of an $L 2$ reading comprehension task borrowed from Philips (Longman complete course for the TOEFL Test: preparation for the computer and paper tests, 2001). A software was programmed based on Campione and Brown's (Dynamic assessment: one approach and some initial data, 1985; Dynamic assessment: an international approach to evaluating learning potential, 1987). Graduated Prompt Approach, an adapted version of Guthke and Beckmann's (Dynamic assessment: prevailing models and applications, 2000), and Aljaafreh and Lantolf's (Mod. Lang. J 78:465-483, 1994) hierarchical presentation of mediations to record the learners' passive RL.

Conclusion: The results reveal that learners' with larger ZPD not only reached the answer with implicit mediations but also reflected shorter RL in reaching the correct answer. The learners' information processing also expedited through presentation of mediations.
\end{abstract}

Keywords: Computerized dynamic assessment (C-DA), Zone of proximal development (ZPD), Response latency (RL)

\section{Introduction}

In the field of psycholinguistics, which studies human's mentality, multidimensional responsibility of cognition for both comprehension and production is not fully apparent. As the backbone of cognition, comprehension is considered as the inseparable and essential abstract operation for creating durable memories (Bransford and Johnson 1972) which the subsequent decisions made (Trabasso and Bartolone 2003). The abstraction in comprehension processes causes difficulty in crystallization of mind procedure of

\section{Springer}

(c) 2016 Bakhoda and Shabani. Open Access This article is distributed under the terms of the Creative Commons Attribution 4.0 International License (http://creativecommons.org/licenses/by/4.0/), which permits unrestricted use, distribution, and reproduction in any medium, provided you give appropriate credit to the original author(s) and the source, provide a link to the Creative Commons license, and indicate if changes were made. 
processing information. To understand these higher and lower-information processing, cognitive psychologists concentrate on the text and discourse comprehension (see Graesser et al. 1997) because of the convenience of presenting context stimuli to reach the rationale behind the comprehension processes. The conflicts such as modular versus interactive (e.g., Fodor 1983; Marslen-Wilson and Tyler 1987), bottom-up versus top-down (e.g., Albrecht and Myers 1995; Graesser et al. 1994; Magliano et al. 2001; McKoon and Ratcliff 1992; Myers and O'Brien 1998) and so on along with different models such as Construction-Integration (CI) model (Kintsch 1988, 1998), StructureBuilding model (Gernsbacher 1997; Gernsbacher et al. 1990), the Constructionist model (Graesser et al. 1994) etc. have been attempting to provide a more vivid picture of how information processing occurs in the human minds.

To delve more deeply into the information processing of the mind, response latency is introduced to "analyze on-going cognitive processes while responding" (Mayerl 2013). Cognitive psychologists believe that the time spent by respondents to answer a question indicates the loading process of mind which is essential for reaching the answer (Draisma and Dijkstra 2004, p. 132). Response latency as a performance measurement, which is the reflection of cognitive processing, commenced to be investigated by Aaker et al. (1980) and LaBarbera and MacLachlan (1979). The time between the respondent receives the question and he/she starts to answer is considered as the response latency (Mulligan et al. 2003) which turns out to be manifested in a continuum of spontaneous versus thoughtful responses (Mayerl 2013). The response latency could be recorded either actively or passively. The former is measured based on the immediate starts and stops of the timer, managed through computer or programs (such as CATI and CAPI), to record learners' time spent in answering the question after the presentation of question while the latter included both the question presentation and the learners' spent time to answer the question. Although they are two types of response latency measurement, the studies by Mulligan et al. (2003) and Mayerl and Urban (2008) demonstrated that the same result could be achieved from both response latencies, active and passive time latency. The achieved time for the respondent goes through statistical analysis to explore the accessibility, strength and stability of respondent's attitude (Draisma and Dijkstra 2004, p. 133). The more accessibility, strength and stability in attitudes and responses tend to quicker reaction to the question, which take fewer time for the respondents, whereas less accessibility, strength, stability in respondent's attitudes bring them greater deal of time (Bassili and Krosnick 2000; Fazio 1990).

In this study, the respondents' response latency is investigated based on the offered mediations through computerized dynamic assessment (C-DA) of reading comprehension. Mediation as a key concept in Vygotsky's sociocultural theory (SCT) is explained by Lantolf (2000) as follow: "the central and distinguishing concept of sociocultural theory is that higher forms of human mental activity are mediated. Vygotsky argued that just as humans do not act directly on the physical world but rely, instead, on tools and labor activity, we also use symbolic tools, or signs, to mediate and regulate our relationships with others and with ourselves" (2000, p. 80). According to the Donato and McCormick (1994), Ableeva (2008) and Lantolf (2010) mediation in L2 context plays the role of instructional intervention which modifies cognitive process and learning. This cognitive modification is expected to influence the respond latency in respondents. 


\section{Literature review}

As the pioneer experts of response latency, Aaker et al. (1980) and LaBarbera and MacLachlan (1979) attempted to measure the response latency in telephone interviews. The respondents were asked about companies and their products via telephone based on the assumption that the quicker the selection between brands, the stronger the preference would be. In a statistical quantitative analysis, MacLachlan and Siegel (1979) ascertained that more time was spent for incorrect answers to the knowledge questions about the companies and the products than correct answers. Their conclusion was that up to a certain level of time the respondents' answer was based on actual knowledge and above that level "helpful guessing" might be used. Bassili (1993) also employed response latency to demonstrate nuances between voting intentions and actual voting behavior. In comparison with a verbal measure of "certainty", response latency was concluded to be a better predicator. Different types of questions are also demonstrated to have an effect on response latency in Bassil and Fletcher (1991) investigation. They ordered the questions according to the respondents' response latency from very short response latency to the long one. The simple factual questions reflected shorter latency than complex attitudinal ones. Poor-prepared questions were also introduced as another factor which could increase the amount of time respondent spent to answer the questions (Bassili 1996a; Bassili and Scott 1996.

The response latency is also employed in social psychology to explore respondents' accessibility, strength, and stability of attitudes. Bassili and Krosnick (2000) and Fazio (1990) explicated that the high accessibility, stability, and strength in respondents' attitude bring shorter response latency while respondents with uncertainty spent more time to answer the questions. The increase of elaboration added more time to the response latency. The extent of elaboration in answering process in accordance with the response latency has been investigated to reach the mode of information processing in mind. Therefore, various applications are introduced in this regard (e.g., Baxter and Hinson 2001; Carlston and Skowronski 1986; Gibbons and Rammsayer 1999; Hertel et al. 2000; Sheppard and Teasdale 2000; Urban and Mayerl 2007).

The measurement of response latency is a crucial issue because the reliability of the gained and interpreted information depends on the meticulous record of response time. The response latency could be recorded either by human or computer. The interviewer might have the responsibility to press the key to run the timer immediately after the last word of the question articulated and stop the timer at the exact moment the respondent begins to respond. In fact the dexterity of the interviewer plays a crucial role in gaining reliable data. On the other hand, computer and technology are employed with the same goal to secure the human error. Bassil and Fletcher (1991) employed voice key and computer to start and stop the timer on the spot. Although employing software sensitive to extraneous sound could have detrimental impact on validity of data like invalid measurement up to $50 \%$ in interviewing due to unrecognizable reaction to the meaningful human sound by the software (Bassil and Fletcher 1991; Bassili 1996b), it is possible to use the modified version of the software to record the passive response latency.

At the level of comprehension generally, the response latency is under the influence of diverse variables which are still in the road of investigation. Although the studies such as Csikszentmihalyi and Getzels (1971) or Gick and Holyoak (1983) indicated that 
less effective problem solvers spent less time to comprehend than creative and effective ones, they did not consider the significant variable of prior knowledge in individuals. More background knowledge about specific issue leads to smooth comprehension due to automatic activation of prior knowledge. At the text level comprehension, Glanzer et al. (1984) and Graesser and Mandler (1975) found that the slower reading time is spent by comprehenders when they stepped in the initial stage of processes such as the first sentence of paragraph or the first sentence of an episode (Haberlandt et al. 1980).

Dynamic assessment (DA), with its root in Vygotsky (1978) sociocultural theory (SCT), is introduced to both assist and assess learners in accordance with what is above their current level of ability or zone of actual development(ZAD). The mediation, also known as intervention, plays crucial role in generating new concepts with the aim of internalization through moving individuals forward along their zone of proximal development (ZPD) (Poehner 2008). Factually, learners travel across the distance between the-current-level ability (ZAD) to near-future potentiality (ZPD) by the mediation. Interactionist and interventionist are two formats of offering mediation to the learners (Lantolf and Poehner 2004). In interactionist format, the mediations are presented through dialogue interaction which is based upon learner's needs while in interventionist format the mediations are prefabricated and for learner's failure one of them would be offered. Computerized presentation of mediations via computerized dynamic assessment (C-DA) context are also widespread these days (Shabani 2012; Shabani and Bakhoda 2014). According to Kozulin (2003, p.17) the students differences before and after the presentation of mediation is the main concern of DA. The differences are expected to be learners' cognitive modification and growth of ZPD.

In this study, we attempted to delve more deeply into the learners' mind to explore the cognitive modification of learners when they required mediation and also investigate their response latency when faced with different prompts (textual to visual) via C-DA in reading comprehension. The software was programmed to both present electronic mediations and record the learners' response latency at different levels.

\section{Research questions}

This study seeks answer(s) for the following research questions:

1. Could response latency be employed as a measurement tool for assessing L2 learners' ZPD?

2. What are the learners' response latencies pattern during the presentation of hierarchical mediations?

3. What is the effect of mediations presentation on learners' information processing during reading comprehension?

4. To what extent response latency could differentiate L2 learners from each other?

\section{Methods}

\section{Study design}

To record learners' passive response latency in reading comprehension, a software was programmed to both offer prefabricated mediations and record the time each learner spent to tackle the correct answer. Aljaafreh and Lantolf (1994), Campione and Brown $(1985,1987)$ 
Graduated Prompt Approach plus an adapted version of Guthke and Beckmann (2000) were employed among other approaches of DA (e.g., Brown and Ferrara 1985; Carlson and Wiedl 1992; Guthke 1993; Poehner: Dynamic assessment of oral proficiency among advanced L2 learners of French, Unpublished; Feuerstein 1979) to be the basic framework of the prompt presentation in the software. Along each presentation of mediation with any quality, the timer played its role to capture the learners' response latency.

\section{Participants}

Voluntarily, 43 intermediate English learners between 14 and 16 years old recruited from Ponaki English Language Institute in Gorgan, Golestan and Puyesh Language Institute in Babol, Mazandaran province participated in this study. Both 20 male and 23 female English language learners at the intermediate level, with three-year experience of studying English in above-mentioned institutes, were involved in this study.

\section{Materials and instruments}

A software, with the use of Java script, was designed to present a reading comprehension text borrowed from Philips (2001) which was manipulated by highlighting and visualizing the text to assist the learners when they failed to select the correct answer. The passage was presented in "Times New Roman" font in 12 size. Ten laptops were employed to install the program in which ten individuals could take part simultaneously in the procedure of the study. As the crucial part of the software, the timer was programed to record each learner's spent time during the responding procedure. The text along with question and mediations are presented in Appendix A.

\section{Procedure}

Individually, each learner was asked to click on the software to read a comprehension text and respond to a multiple choice question with ten options. When a learner clicked on the software's icon, the text appeared on the screen. Each learner read the passage while the timer started simultaneously with the appearance of the text on the screen. The timer continued to count until the learner selected an option. If the selected option was the correct answer in the first attempt, the timer saved the time as "the response latency without receiving any mediation" for the correct answer. If the selected option was the incorrect option, the time was saved as "the response latency of incorrect answer". Meanwhile, for the incorrect attempt, the first text-based mediation (the most implicit one) was offered to assist the learner with a new timer which was responsible to capture the learner's response latency in the second attempt. This procedure continued up to the sixth attempt. The continuation of selecting the incorrect options made the software present more and more explicit predetermined prompts until the last attempt (six) where the most explicit mediation (third picture) was offered by the software. Through learner's selection, either correct or incorrect at any level, each learner's response latency was recorded by the software with the consideration of mediation's quality and the in/correctness of the answer. The following Figure demonstrates the framework of the software:

Figure 1 demonstrates the procedure of C-DA from beginning to the end. The works of timer along with the quality of mediation, the degree of explicitness/implicitness and 


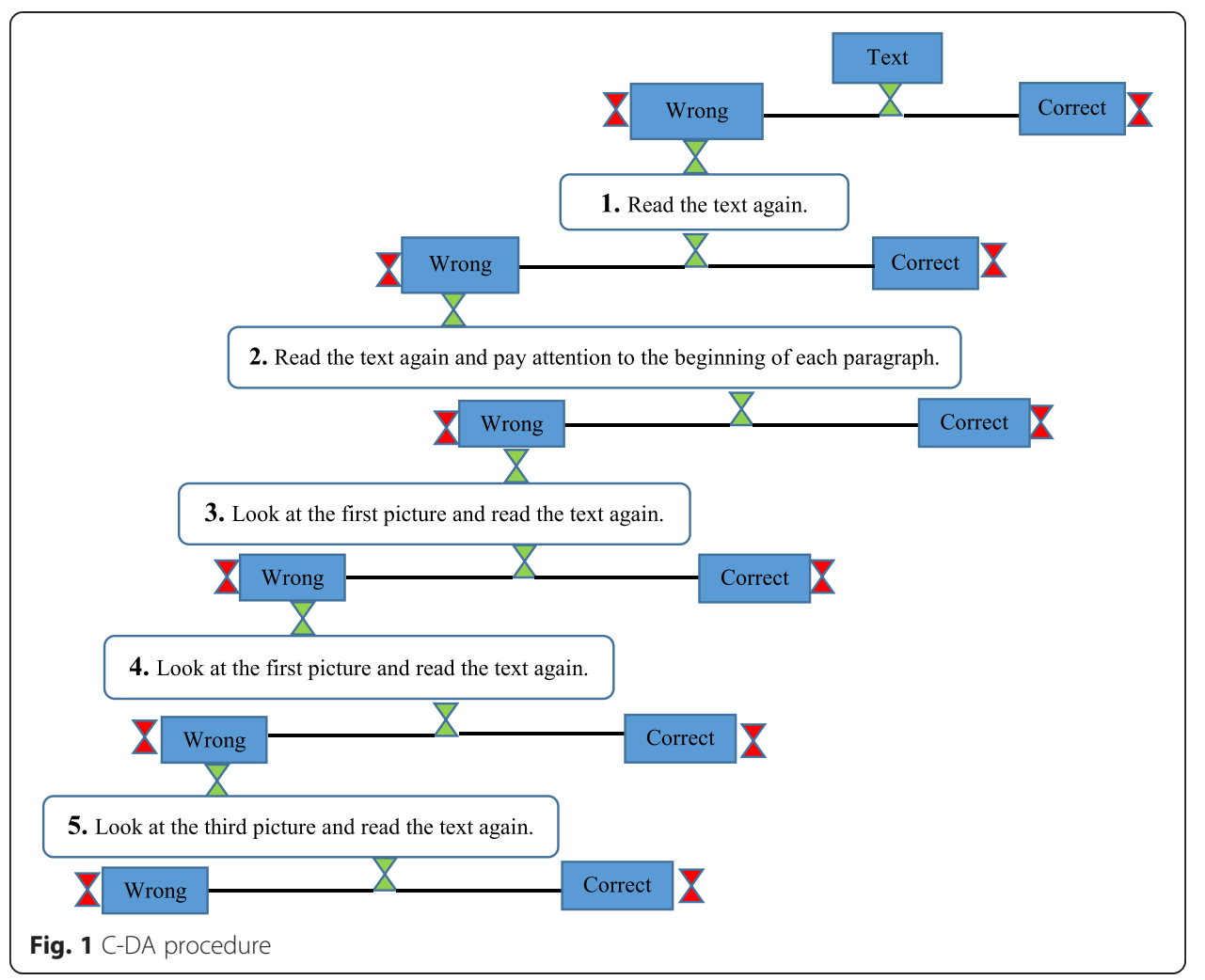

whether the mediations were textual or visual, are graphically demonstrated in Fig. 1. The rationale behind this procedure is as follow: first, the mediations during the reading comprehension text could accelerate the processing information in mind which concomitantly brought shorter response latency to the respondents; second, learners with larger ZPD had shorter response latency than those with smaller ones; third, the quality of mediations, ex/implicitness, had an effect on response latency of respondents even those with smaller ZPD.

\section{Data analysis}

The C-DA of reading comprehension task provides us with the learners' profile. These profiles are compromised of the number of each learner's attempt, the time each learner spent to reach the answer, the correctness or incorrectness of selection, and with/without mediation the correct answer was selected. The collected data from learners' performance in the C-DA are encapsulated in the following table:

In Table 1, the information pertaining to the learners' performance are firstly classified based on their attempts. Generally, the C-DA provided each learner with six attempts to arrive at the correct answer in the reading comprehension task. Learners' overall attempts are classified under the attempts' title. The last attempt, sixth, is separated into two attempts (sixth 1 and sixth 2 ) because there was no further opportunity and mediation. The sixth 1 represents successful attempts while sixth 2 manifests unsuccessful attempts. The learners' response latency of successful attempts, based on second, is classified under the title of "time of correct answer". Both the least and the longest response latency are included for the successful attempts. The general response latency of learners, whether the correct answer was tackled or not, are sorted in 
Table 1 The C-DA result (Visual $=V$, Manipulate $=$ Man)

\begin{tabular}{llllll}
\hline Attempts & Time of correct answer & General time & Task features & ZPD level & N \\
\hline First & $121-197$ & $56-318$ & Text & 60 & 6 \\
Second & $40-101$ & $40-271$ & Man. Text 1 & 50 & 8 \\
Third & $51-181$ & $51-200$ & Man. Text 2 & 40 & 7 \\
Fourth & $83-103$ & $81-162$ & Man. Text + V1 & 30 & 5 \\
Fifth & $61-67$ & $49-133$ & Man. Text + V2 & 20 & 2 \\
Sixth 1 & $13-88$ & $13-129$ & Man. Text + V3 & 10 & 9 \\
Sixth 2 & ---- & $29-129$ & ---- & --- & 6 \\
\hline
\end{tabular}

association with each attempt in the general time column. Task features summed up the quality of mediations which were offered hierarchically from the most implicit prompts to the most explicit prompts to assist the learners in reaching the correct answer. Learners' ZPD level is calculated in accordance with the assumption underlying ZPD and mediation in Vygotsky's SCT. Based on SCT, learners with developed ability required no mediation while learners with developing ability required assistance to move beyond their current level of ability (Kozulin 2003). Therefore, for each presentation of mediation 100 score was subtracted from 600 based on six opportunity for reaching the correct answer. The last column contains both the number of learners who answered the question successfully and those who failed.

The learners' responses are analyzed at the following three levels: a) general response latency of all the learners in accordance with the mediation and the in/correctness of the attempts; b) meticulous analysis of response latency in the successful attempts; and c) meticulous analysis of response latency in unsuccessful attempts.

\section{Learners' response latency vs. their ZPD levels}

Involved in the C-DA procedure, the learners could reach the answer or not. The learners' response latency fluctuated, by running the gamut of mediation in the C-DA for failed attempts. An overall look at the learners' response latency in the following Fig. 2 could explicate the differences among the learners.

This histogram represents learners' response latency in accordance with their duration of correct responses and their ZPD level. The blue bars manifest learners'

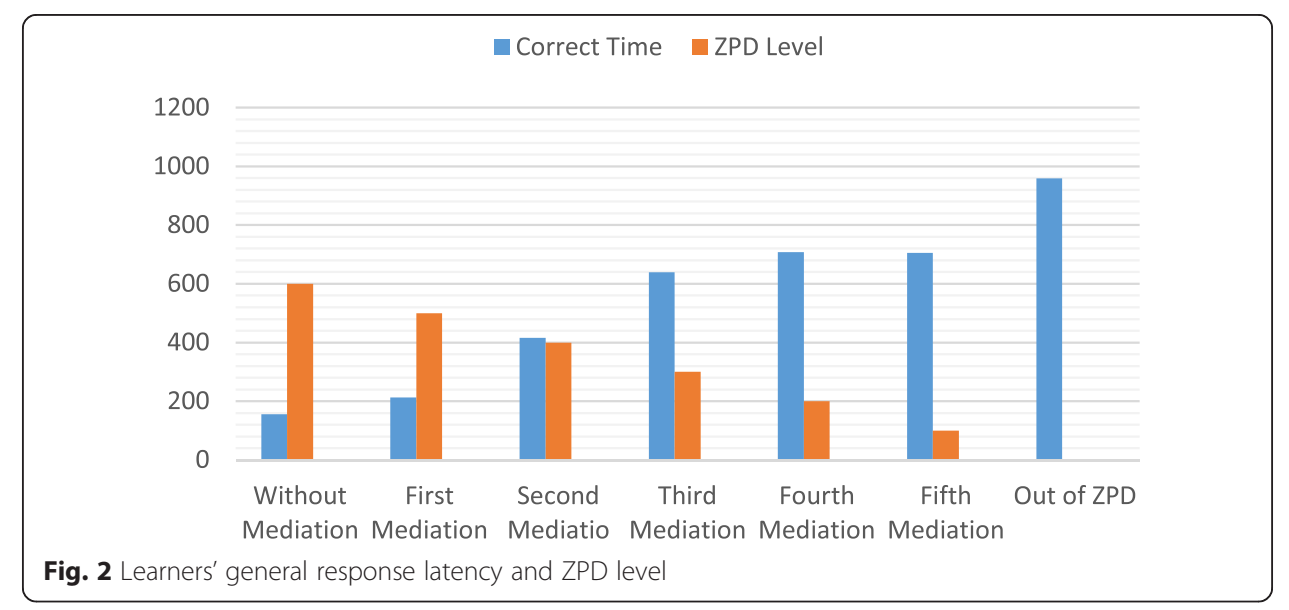


response latency of correct answer in association with the offered mediations, while orange bars depict learners' ZPD level. Learners with larger ZPD demonstrate to reach the correct answer with shorter response latency. For example, the learners who correctly answered the question with the first attempt (with no mediation) elicited shorter processing information than those who required mediations in arriving at the correct answer. On the other hand, learners who were not able to tackle the correct answer, despite the presentation of all mediations, demonstrated the longest response latency which was the result of longer information processing. As it is apparent in Fig. 2, the hierarchal presentation of mediation via C-DA caused fluctuation in learners' response latency. Learners who tackled the correct answer through the first mediation, the most implicit one, indicated shorter latency in response for correct answer than those who reached the correct answer with the second and third mediations. With the gradual increase of mediations' explicitness for failed learners, the learners' response latency for correct answer gradually increased. Successful learners with the use of fifth mediation, the most explicit one, had the longest response latency of the correct answer while failures (out of ZPD) at the last attempt had the longest latency in responses.

\section{Response latency of correct answer}

A more vivid picture of learners' response latency of correct answers and concomitantly their processing time is provided in the following scatter plot Figure:

This scattered plot in Fig. 3 demonstrates more meticulously the exact latency of each learner in arriving at the correct answer. Although Fig. 2 represented the learners' overall response latency regard with the offered mediations, each individual's response latency remained unclear. In sum, Fig. 3 demonstrates individual's response latency of successful attempts based on the mediations they received. Each blue point is the manifestation of individuals' correct answer in accordance with his/her response latency and the mediation(s) he/she received. Same as Fig. 2, learners in level 0 are fully developed learners who reached the answer without any mediation. According to Fig. 3, the differentiation among learners is more distinguishable based upon their response latency. Although learners at 0 level arrived at the correct answer without receiving any mediation, they demonstrated different response latency. More precisely, response latency accentuates differentiation among learners' developed ability of reading comprehension. Learner's growing ability also distinguished based upon their response latency.

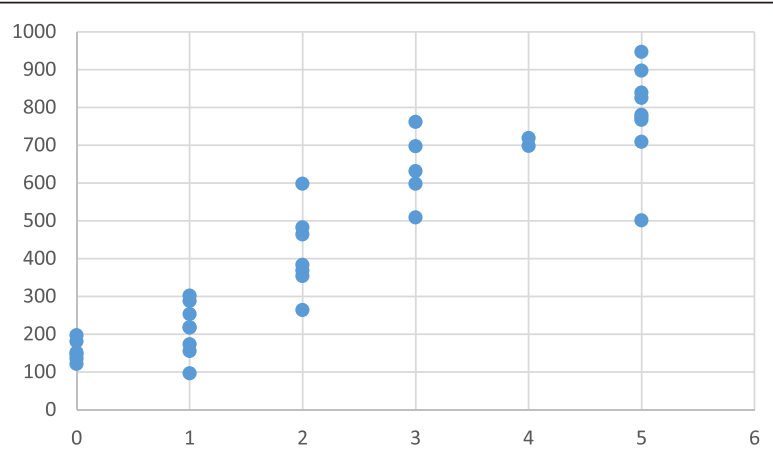

Fig. 3 Individualistic response latency 
Learners with close proximity to fully-developed ability in level 2 were also observed to arrive at the correct answer with distinguishable response latency, though they reached the correct answer with the same mediation. The narrow crack, as the sign of learners' differentiation in response latency, among blue points in 0 level becomes more conspicuous with the increase of mediations' explicitness in level 2-6.

\section{Mediations and response latency}

To delve more deeply into the learners' on-going information processing, the following graph provides us with the learners' response latency of both un/successful attempts with the consideration of presented mediation in each attempt.

The learners' response latency in tackling the answer at each attempt is demonstrated in the above histogram (Fig. 4). A specific color is devoted to the learners' response latency in each attempt. For example, blue bars demonstrate learners' first attempt which was without any mediation or orange bars represent learners' second attempt which was at the presence of first implicit mediation. The effect of mediations on learners' ongoing cognitive information processing could be crystallized through comparing learners' response latency before and after the presentation of mediations. The presentation of first and the most implicit mediation not only made some learners come up with the correct answer (in second attempt) but also expedited their information processing which resulted in shorter response latency. Besides, this acceleration of information processing also observed in the learners' unsuccessful attempt (orange bar at the third attempt). Leaners' response latency even decreased with the presentation of second mediation (gray bar), which was more explicit than the first one. By increasing the explicitness of mediations toward the last attempt, the learners' response latency decreased. Even failed learners' response latency at the last attempt (sixth, II) declined toward the last and wrong attempt.

\section{Results}

The combination of time with the mediation via C-DA provided us with an opportunity to analyze the learners' on-going cognitive processes. Instead of entangling in dichotomy of spontaneous versus thoughtful response latency, learners' response latencies were analyzed in accordance with the mediations they received. The obtained results from empirical analysis of the collected data are categorized as follow: a) successful

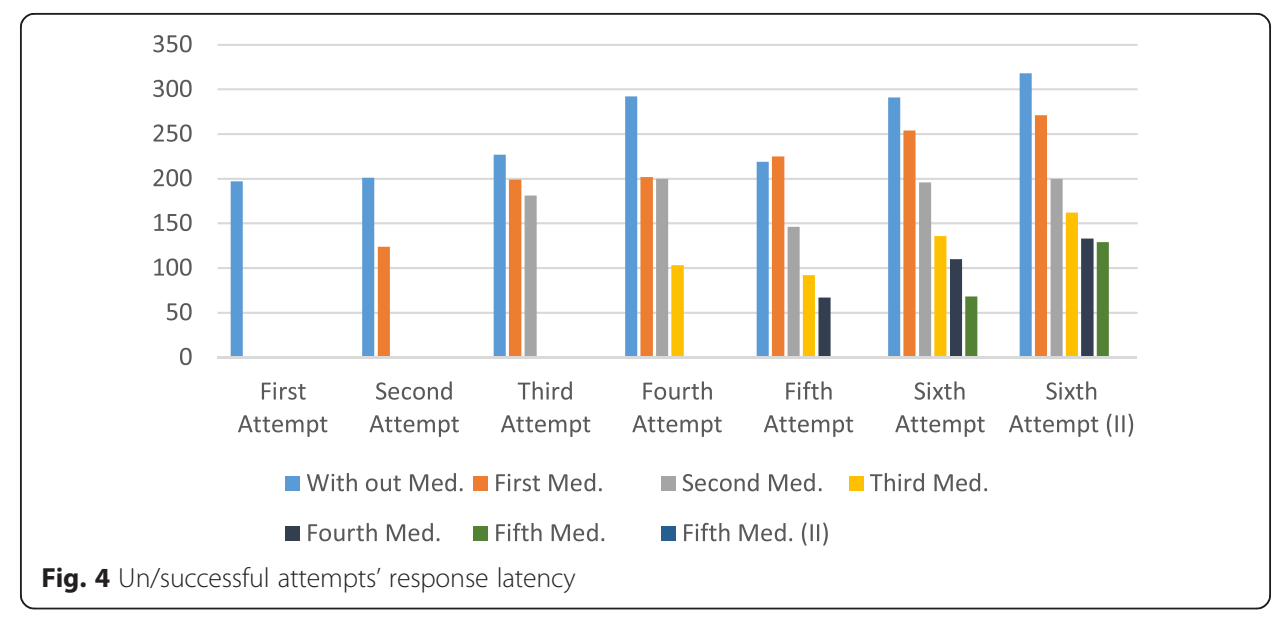


learners' processing information; b) individualistic difference in response latency; c) the general effect of mediation on learners' response latency.

\section{Response latency of developed and developing reading ability}

The analyzed data from the learners' performance in C-DA indicated that learners with developed ability in reading comprehension reflects shorter response latency in reaching the correct answer than those in embryonic stage of developing. The developed ability of comprehending the passage brought shorter accessibility to the required multidimensional information processing which resulted in shorter response latency for fully developed learners who reached the correct answer without any mediation. On the other hand, learners' fledgling ability in comprehending the passage, which was boosted by plethora of assistance, indicated different response latencies in reaching the correct answer. The implicit mediation bred instant access to the required information which resulted in facilitation of processing the information and concomitantly shorter response latency. The closer proximity to ZAD in reading comprehension not only required less explicit prompts to reach the answer but also manifested shorter response latency. Although the decrease of response latency was obvious in unsuccessful learners spent time, the presentation of all mediations was fruitless for them in arriving at the correct answer. Due to not having the task on their ZPD, the failed learners were unsuccessful in reaching the answer. But their information processing expedited with the presentation of mediation.

\section{Individualistic difference in response latency}

Integration of question with assistance in the C-DA crystallized the individual differences at the levels of ZAD, ZPD, and response latency. The conspicuous question in assessing learners' ZAD based on conventional non-dynamic assessment is whether learners correctly answered the question. Without receiving any mediation, six learners demonstrated that they had the task in their ZAD by reaching the correct answer. The differentiation of these learners in comprehending the passage was perceptible through each learner's response latency during coming up with the correct answer. Shorter response latency was the result of quicker information processing in learners with stronger ZAD. Learners' nuances of developed reading comprehension potentiality manifested itself in required processing information for answering the question which was concretely represented itself in the latency of responses. Therefore, the difference in ZAD brought individualistic response latency for each learner. On the other hand, learners' proximity to the ZAD was measured both by offering ex/implicit mediations and recording their spent time in reaching the correct answer. Although separate consideration of offered mediation could elucidate learners' ZPD, the difference among those who reached the correct answer with the same mediation remained mysterious. Learners' response latency demonstrated to be distinctive both for the group of learner and individuals. Those who reached the correct answer through an implicit mediation reflected shorter response latency than those who arrived at the correct answer with the help of explicit mediation. The response latency even differentiates learners who believed to have equal potentiality due to reaching the correct answer with a particular mediation. Each individual manifests particular response latency in arriving at the correct answer. Even each unsuccessful learner in reaching the correct answer (six learners) shows individualistic response latency. 


\section{Effect of mediations on learners' response latency}

The prefabricated mediations via C-DA were offered to assist learners' developing abilities for comprehending the passage. The hierarchical arrangement of mediations brought fluctuation of response latency in learners with different ZPD enlargements. The implicit (textual) to the explicit (visual) mediations were employed to both assist the learners to reach the answer and reveal their ZPDs in accordance with their response latency. By the gradual increase of mediations' explicitness, learners' response latency decreased at each level. More direct assistance in explicit mediations not only accelerated learners' information processing but also decreased learners' response latency. Even failed learners reflected acceleration in their information processing during hierarchical presentation of mediation, as shown in Fig. 4. Although mediations measured learners' ZPD, the meticulous individualistic measurement occurred through the learners' response latency. The quicker accessibility and processing information was the result of mediations presentation for the learners with larger ZPD. The multidimensional role of mediation manifested, in Fig. 4, to be beyond the superficial consideration of assistance in leading the learners to reach the answer.

\section{Discussion and conclusion}

This study was designed to investigate primarily the learners' response latency in the C-DA form of reading comprehension task. A software was responsible for capturing the learners' response latency alongside presenting explicit to implicit mediations through a computerized form of DA. The software was programmed to record the learners' response time while they attempted to answer the reading comprehension question in C-DA. To investigate the effect of mediation on learners' response latency, Aljaafreh and Lantolf (1994) regulatory scale was employed in the gradual presentation of mediation for the failed attempts during the C-DA. Deep analysis of the collected data led to the following observations:

\section{Response latency and Vygotsky's SCT}

To elaborate on the essence of both biological and cognitive growth for development, Vygotsky (Vygotsky 1994, p. 65) introduced the concept of internalization which is believed to form in departure from inter-psychological plane to intra-psychological plane. Fully developed ability manifests itself at the level of intra-psychology where a child independently performs a task. The learners' response duration along with assistance explicates how far learners are from independency and how long information processing takes for each learner to arrive at the correct answer. Fully developed ability at the intra-mental level brings greater accessibility, strength, and stability in processing information for the learners. Short response latency in social psychologists' investigation such as Bassili and Krosnick (2000), Fazio (1990), and Johnson et al. (1999) is attributed to the stronger, more accessible, and more stable attitude. The findings of this study, as indicated in data analysis and results, are not only in line with the results of Bassili and Krosnick (2000), Fazio (1990), and Johnson et al. (1999) but also show fluctuation of response latency for learners with different levels of proximity to ZAD in reading comprehension task. Cognitive functioning in learners with larger ZPDs not only boosted with more implicit mediation in reaching the answer (Antón, 2003 and Aljaafreh and 
Lantolf 1994) but also attested shorter response latency. In other words, learners' ongoing information processing is affected by transferring from developing ability (ZPD) to developed ability (ZAD) through assistance. Mediations expedite the load of information processing for learners with different ZPD enlargements which conspicuously decrease their response latency.

\section{Response latency and reading comprehension}

The findings of this study also reject the claim that less effective problem solvers spent shorter time in comprehending a text than more effective and creative ones (Csikszentmihalyi and Getzels 1971; Gick and Holyoak 1983). But, reading comprehension is the result of complex operation of lower and higher-level processes (Balota, Flores d'Arcais, \& Rayner, 1990) which represents itself in learners' response latency. Mental representation of a text is the result of processing information from the text, information that is related to the text, and the inferences that are generated (McNamara and Magliano 2009) in which deficiency in any of them brings further loading to the information processing and concomitantly longer response latency. The implicit to explicit presentation of mediations bridged these parts hierarchically to assist activation of prior knowledge, which could be related to the text, and reasonable inferences in leading the learners beyond their current level of comprehension. Continuous activation of prior knowledge during the reading is boosted by mediation for further assistance which substantiated McNamara and Magliano (2009) statement "When comprehenders have more knowledge about the domain, or about the world, then their understanding will be more rich and coherent because more concepts are automatically primed" (p.303). This superactivation by mediation also manifested itself in learners' shorter response latency. For learners with different reading comprehension ability, different textual (implicit) and visual (explicit) mediations are required to assist them to fully understand the passage and reach the correct answer. But, we cannot neglect other variables such as the strategies readers used, their goal, and their metacognitive awareness which could bring further load to the processing information in longer time or expedite it in shorter time (McNamara, 2007).

On the implication side, mediators could use different kinds of mediations to assist learners in comprehending a passage instead of letting them struggle with difficult vocabularies by their own. Both textual and visual mediations could end learners' ongoing struggle against words and provide them with the opportunity to keep focus on crucial information for reading comprehension. The learners' high processing time at their initial attempts might relate to such peripheral emphasis on vocabularies. Besides, response latency could clearly differentiate learners form each other when they reach the answer with the same mediation. Consideration of mediations' quality and learners' response latency could better crystallize learners' performance when assessment is necessary.

Response latency as the manifestation of ongoing information processing could provide us with more vivid picture of comprehension by considering the role of long term memory, working memory, working memory, word knowledge, world knowledge and so on. Also, the effect of visual based mediation versus text based mediation on reading comprehension and response latency could move further our understanding of mental operation in comprehending a text. 


\section{Appendix A}

\section{Read the following text and answer the question:}

The rate at which the deforestation of the world is proceeding is alarming. In 1950 approximately 25 percent of the earth's land surface had been covered with forests, and less than twenty-five years later the amount of forest land was reduced to 20 percent. This decrease from 25 percent to 20 percent from 1950 to 1973 represents an astounding 20 million square kilometers of forests. Predictions are that an additional 20 million square kilometers of forest land will be lost by 2020 .

The majority of deforestation is occurring in tropical forests in developing countries, fueled by the developing countries' need for increased agricultural land and the desire on the part of developed countries to import wood and wood products. More than 90 percent of the plywood used in the United States, for example, is imported from developing countries with tropical rain forests. By the mid-1980s, solutions to this expanding problem were being sought, in the form of attempts to establish an international regulatory organization to oversee the use of tropical forests.

The author's main purpose in this passage is to....

(A) cite statistics about an improvement on the earth's land surface

(B) explain where deforestation is occurring

(C) blame developing countries for deforestation

(D) how deforestation occurs in the world

(E) offer solutions for deforestation

(F) inform reader about history of deforestation

(G) predict what will happen in 2020

(H) report that deforestation began in United States

(I) find the main source of deforestation

(J) make the reader aware of a worsening world problem

\section{Mediations:}

1. Read the text again

2. Read the text again and pay attention to the beginning of each paragraph.

3. Look at the first picture and read the passage again (picture 1).

4. Look at the second picture and read the passage again (picture 2).

5. Look at the third picture and read the passage again (picture 3 ).

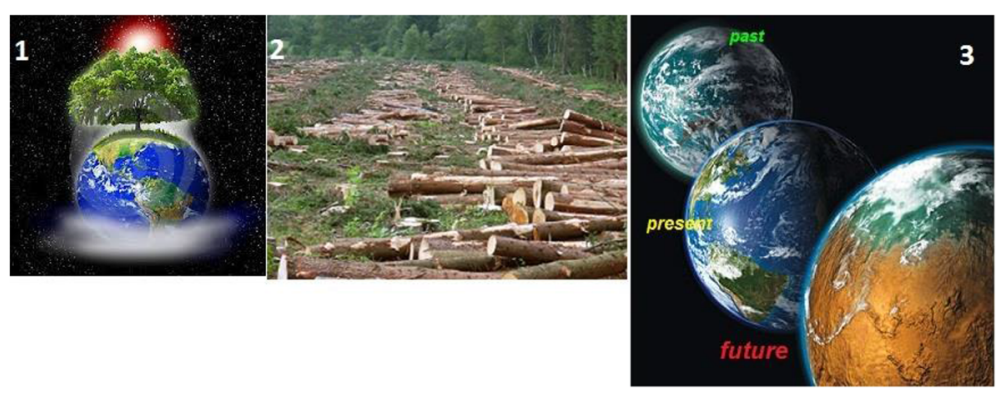




\section{Competing interests}

The authors declare that they have no competing interests.

\section{Authors' contributions}

IB and KS carried out the research by the title of "Response latency as a tool to study L2 Learners' ZPD, ZAD and ongoing information processing" and participated in the sequence alignment and drafted the manuscript. Both authors read and approved the final manuscript.

\section{Authors' information}

Iman Bakhoda is an MA graduate of TEFL from Allameh Mohaddes Nouri University, Iran. He has published a paper in humanizing language teaching journal and presented several papers in national and international conferences like Tellsi12, IELTI-7, and CELT-EL2015. He is interested in doing research on dynamic assessment and discourse analysis. Karim Shabani is a PhD graduate of TEFL from the University of Tehran and academic member of Allameh Mohaddes Nouri University. He has presented a number of papers in international conferences like ICELT2009 (UPM), TELLSI6, TELLSI7, TELLSI9, TELLSI10, TELLSI11, ILI conference, ICELET2012 (University of Tehran), etc. His areas of interest are Vygotsky's Socio-cultural Theory, (dynamic) testing/assessment and simultaneous interpreting.

\section{Received: 13 October 2015 Accepted: 23 January 2016}

Published online: 14 April 2016

\section{References}

Aaker, DA, Bagozzi, RP, Carman, JM, \& Maclachan, JM (1980). On using response latency to measure preference. Journal of Marketing Research, 17, 237-244.

Ableeva, R (2008). The Effects of Dynamic Assessment on L2 Listening Comprehension. In J. P. Lantolf, \& M. E. Poehner (Eds.), Sociocultural Theory and the Teaching of Second Languages (pp. 57-86). London: Equinox.

Albrecht, JE, \& Myers, JL (1995). The role of context in the accessibility of goals during reading. Journal of Experimental Psychology: Learning, Memory, and Cognition, 21, 1459-1468.

Aljaafreh, A, \& Lantolf, JP (1994). Negative feedback as regulation and second language learning in the zone of proximal development. Modern Language Journal, 78, 465-483.

Antón, M (2003). Dynamic Assessment of Advanced Foreign Language Learners. Paper Presented at the Meeting of the American Association of Applied Linguistics, Washington, DC.

Balota, DA, Floresd'Arcais, GB \& Rayner, K (Eds.) (1990). Comprehension processes in reading. Hillsdale, NJ: Erlbaum.

Bassil, JN, \& Fletcher, JF (1991). Response-time measurement in survey research-a method for CATI and a new look at non-attitudes. Public Opinion Quarterly, 55, 331-346.

Bassili, JN (1993). Response latency versus certainty as indexes of the strength of voting intentions in a CATI survey. Public Opinion Quarterly, 57, 54-61.

Bassili, JN (1996a). Meta-judgmental versus operative indexes of psychological attributes: the case of measures of attitude strength. Journal of Personality and Social Psychology, 71, 637-653.

Bassili, JN (1996b). The how and why of response latency measurement in telephone surveys. In N. Schwarz \& S. Sudman (Eds.), Answering questions: methodology for determining cognitive and communicative process in survey research (pp. 319-346). San Francisco: Jossey-Bass.

Bassili, JN, \& Krosnick, JA (2000). Do strength-related attitude properties determine susceptibility to response effects? New evidence from response latency, attitude extremity, and aggregate indices. Political Psychology, 21(1), 107-132.

Bassili, JN, \& Scott, BS (1996). Response latency as a signal to question problems in survey research. Public Opinion Quarterly, 60, 390-399.

Baxter, BW, \& Hinson, RE (2001). Is smoking automatic? demands of smoking behavior on attentional resources. Journal of Abnormal Psychology, 110(1), 59-66.

Bransford, JD, \& Johnson, MK (1972). Contextual prerequisites for understanding: some investigations of comprehension and recall. Journal of Verbal Learning and Verbal Behavior, 11, 717-726.

Brown, AL, \& Ferrara, RL (1985). Diagnosing zones of proximal development. In J. V. Wertsch (Ed.), Culture, communication, and cognition: Vygotskian perspectives (pp. 273-305). Cambridge: Cambridge University Press.

Campione, JC, \& Brown, AL (1985). Dynamic assessment: one approach and some initial data. Champaign: University of Illinois at Urbana-Champaign.

Campione, JC, \& Brown, AL (1987). Linking dynamic assessment with school achievement. In C. S. Lidz (Ed.), Dynamic assessment: an international approach to evaluating learning potential (pp. 82-115). New York: The Guilford Press.

Carlson, JS, \& Wiedl, KH (1992). Principles of dynamic assessment: the application of a specific model. Learning and Individual Differences, 4, 153-166.

Carlston, DE, \& Skowronski, JJ (1986). Trait memory and behavior memory: the effects of alternative pathways on impression judgment response times. Journal of Personality and Social Psychology, 50(1), 5-13.

Csikszentmihalyi, M, \& Getzels, JW (1971). Discovery-oriented behavior and the originality of creative products: a study with artists. Journal of Personality and Social Psychology, 19, 47-52.

Donato, R, \& McCormick, DE (1994). A sociocultural perspective on language learning strategies: the role of mediation. The Modern Language Journal, 78(4), 453-464.

Draisma, S, \& Dijkstra, W (2004). Response latency and (Para) linguistic expressions as indicators of response error. In S. Presser, J. M. Rothgeb, M. P. Couper, J. T. Lessler, E. Martin, J. Martin, \& E. Singer (Eds.), Methods for testing and evaluating survey questionnaires (pp. 131-147). New York: Wiley.

Fazio, RH (1990). A practical guide to the use of response latency in social psychological research. In C. Hendrick \& M. S. Clark (Eds.), Review of personality and social psychology (Research methods in personality and social psychology, pp. 74-97). Newbury Park: Sage Publications. 
Feuerstein, R (1979). Dynamic assessment of cognitive modifiability in retarded performers: the learning potential assessment device. In B. B. Wolman (Ed.), International encyclopedia of neurology, psychiatry, psychoanalysis and psychology. New York: Section XII.

Fodor, J (1983). The modularity of mind: an essay on faculty psychology. Cambridge: MIT Press.

Gernsbacher, MA (1997). Two decades of structure building. Discourse Processes, 23, 265-304.

Gernsbacher, MA, Varner, KR, \& Faust, M (1990). Investigating differences in general comprehension skill. Journal of Experimental Psychology: Learning, Memory, and Cognition, 16, 430-445.

Gibbons, H, \& Rammsayer, $T$ (1999). Auswirkungen der vertrautheit mit einer reizdimension auf entscheidungs $\neg$ prozesse: Der modulierende einfluss kontrollierter vs. Automatischer informationsverarbeitung. In I. Wachsmuth \& B. Jung (Eds.), Fachtagung der Gesellschaft für Kognitionswissenschaft (pp. 159-164). Bielefeld: St.Augustin.

Gick, ML, \& Holyoak, KJ (1983). Schema induction and analogical transfer. Cognitive Psychology, 15, 1-38.

Glanzer, M, Fischer, B, \& Dorfman, D (1984). Short-term storage in reading. Journal of Verbal Learning and Verbal Behavior, 23, 467-486.

Graesser, AC, \& Mandler, G (1975). Recognition memory for the meaning and surface structure of sentences. Journal for Experimental Psychology, 104, 238-248.

Graesser, AC, Singer, M, \& Trabasso, T (1994). Constructing inferences during narrative text comprehension. Psychological Review, 101, 371-395.

Graesser, AC, Millis, KK, \& Zwaan, RA (1997). Discourse comprehension. In J. T. Spence, J. M. Darley, \& D. J. Foss (Eds.), Annual review of psychology. Palo Alto: Annual Reviews.

Guthke, J (1993). Developments in learning potential assessment. In J. H. M. Hamers \& K. Sijtsma (Eds.), Learning potential assessment: theoretical, methodological and practical issues (pp. 43-67). Amsterdam: Swets \& Zeitlinger.

Guthke, J, \& Beckmann, JF (2000). The learning test concept and its applications in practice. In C. S. Lidz \& J. G. Elliott (Eds.), Dynamic assessment: prevailing models and applications. Amsterdam: Elsevier.

Haberlandt, K, Berian, C, \& Sandson, J (1980). The episode schema in story processing. Journal of Verbal Learning and Verbal Behavior, 19, 635-650.

Hertel, G, Neuhof, J, Theuer, T, \& Kerr, NL (2000). Mood effects on cooperation in small groups: does positive mood simply lead to more cooperation? Cognition \& Emotion, 14(4), 441-472.

Johnson, M, Shively, WP, \& Stein, RM (1999). Contextual Data and the Study of Elections and Voting Behavior: Connection Individuals to the Environment. Paper presented on the Workshop in Political Theory and Policy Analysis, Indiana University.

Kintsch, W (1988). The role of knowledge in discourse comprehension: a construction-integration model. Psychological Review, 95, 163-182

Kintsch, W (1998). Comprehension: a paradigm for cognition. New York: Cambridge University Press.

Kozulin, A (2003). Psychological tools and mediated learning. In A. Kozulin, B. Gindis, V. S. Ageyev, \& S. M. Miller (Eds.), Vygotsky's educational theory in cultural context. Cambridge: Cambridge University Press.

LaBarbera, PA, \& MacLachlan, J (1979). Time-compressed speech in radio advertising. Journal of Marketing, 43(1), 30-36.

Lantolf, JP (2000). Sociocultural theory and second language learning. Oxford: Oxford University Press.

Lantolf, JP (2010). Sociocultural theory and the pedagogical imperative. In R. Kaplan (Ed.), Handbook of applied linguistics, 2nd ed. Oxford: Oxford University Press.

Lantolf, JP, \& Poehner, ME (2004). Dynamic assessment: bringing the past into the future. Journal of Applied Linguistics, $1,49-74$

MacLachlan, J, \& Siegel, MH (1979). Reducing the costs of TV commercials by use of time compression. Journal of Marketing Research, 17(1), 52-57.

Magliano, JP, Miller, J, \& Zwaan, RA (2001). Indexing space and time in film understanding. Applied Cognitive Psychology, $15,533-545$.

Marslen-Wilson, W, \& Tyler, L (1987). Against modularity. In J. Garfield (Ed.), Modularity in knowledge representation and natural-language understanding (pp. 37-62). Cambridge: MIT Press.

Mayerl, J (2013). Response Latency Measurement in Surveys. Detecting Strong Attitudes and Response Effects. Survey Methods: Insights from the Field. http://surveyinsights.org/? $\mathrm{p}=1063$.

Mayerl, J, \& Urban, D (2008). Antwortreaktionszeiten in survey-analysen: messung, auswertung und anwendungen. Wiesbaden: VS Verlag.

McKoon, G, \& Ratcliff, R (1992). Inference during reading. Psychological Review, 99, 440-466.

McNamara, DS. (Ed.). (2007). Reading Comprehension Strategies: Theory, Interventions, and Technologies. Mahwah, NJ: Erlbaum.

McNamara, DS, \& Magliano, JP (2009). Towards a comprehensive model of comprehension. In B. Ross (Ed.), The psychology of learning and motivation (pp. 284-297). New York: Elsevier.

Mulligan, K, Grant, JT, Mockabee, ST, \& Monson, JQ (2003). Response latency methodology for survey research: measurement and modeling strategies. Political Analysis, 11(3), 289-301.

Myers, JL, \& O'Brien, EJ (1998). Accessing the discourse representation during reading. Discourse Processes, 26, 131-157.

Philips, D (2001). Longman complete course for the TOEFL test: preparation for the computer and paper tests. London: Longman.

Poehner, ME (2008). Dynamic Assessment: A Vygotskian Approach to Understanding and Promoting Second Language Development. Berlin: Springer Publishing.

Shabani, K (2012). Dynamic assessment of L2 Learners' reading comprehension processes: a vygotskian pperspective. Proccedia Social and Behavioral Sciences, 32, 321-328.

Shabani, K, Bakhoda, I (2014). Mediated Functioning and Processing Time as a Measure of L2 Learners' ZPD Performance. Humanizing Language Teaching. 16(3). http://www.hltmag.co.uk/jun14/mart03.htm.

Sheppard, LC, \& Teasdale, JD (2000). Dysfunctional thinking in major depressive disorder: a deficit in metacognitive monitoring? Journal of Abnormal Psychology, 109(4), 768-776.

Trabasso, T, \& Bartolone, J (2003). Story understanding and counterfactual reasoning. Journal of Experimental Psychology: Learning, Memory, and Cognition, 29, 904-923. 
Urban, D, \& Mayerl, J (2007). Antwortlatenzzeiten in der survey-basierten Verhaltensforschung. Kö/ner Zeitschrift für Soziologie und Sozialpsychologie, 59(4), 692-713.

Vygotsky, LS (1978). Mind in society: The development of higher psychological processes. Cambridge: Harvard University Press.

Vygotsky, LS (1994). The problem of the cultural development of the child. In R Van der Veer \& J Valsiner (Eds.), The Vygotsky reader. Cambridge: Blackwell.

Submit your manuscript to a SpringerOpen ${ }^{\odot}$ journal and benefit from:

- Convenient online submission

- Rigorous peer review

- Immediate publication on acceptance

- Open access: articles freely available online

- High visibility within the field

- Retaining the copyright to your article

Submit your next manuscript at $>$ springeropen.com 